\title{
PENGARUH BILAS LAMBUNG NACL 0,9\% TERHADAP STATUS HEMODINAMIK PADA PASIEN STRES ULCER DENGAN POST CRANIOTOMY ATAS INDIKASI CIDERA KEPALA BERAT DI RUANG INTENSIF RUMAH SAKIT UMUM DAERAH Dr. MOEWARDI SURAKARTA
}

\author{
Astrini Rachma Putri, Rita Benya Adriani \\ Kementerian Kesehatan Politeknik Kesehatan Surakarta Jurusan Keperawatan
}

\begin{abstract}
Gastric Lavage, Ulcer Stress, Hemodynamic Status. Severe injury on head with post-craniotomy in the intensive room needs tight supervisory related to the pressure of intracranial in which can produce risk of physiological stress, i.e. acute gastrointestinal bleeding (ulcer stress) which can disturb the hemodynamic status (MAP, artery). One of therapies which can be applied is gastric lavage. This pupose to know the effect of gastric lavage of $\mathrm{NaCl} 0.9 \%$ to the status of hemodynamic to the patient of ulcer stress with post-craniotomy by the indication of severe injury on head in the intensive room of Dr. Moewardi Hospital in 2015. This research is experimental research by cross sectional design for 30 patients with ulcer stress of post-craniotomy by the indication of severe injury on head and treated with gastric lavage of $\mathrm{NaCl} 0.9 \%$ in the ICU and HCU of Dr. Moewardi Hospital during March-April 2015. The statistical analysis applied is Paired Sample T-Test. According to statistical test, the result of $t$ MAP 4,033 with the value of $p$ 0,000 and the artery result of 4,359 with the value of $p 0,000$, in which t table is 2.045 and the criteria of $p<0.05$. Thus, the value of $t_{h} M A P>t_{t}, t_{h}$ artery $>t_{t}$, and the result of MAP $p 0,000(<0.05)$ and artery $p 0,000$. There is a meaningful influence to the hemodynamic status in the ulcer stress patient with with post-craniotomy by the indication of severe injury on head who is treated with gastric lavage of $\mathrm{NaCl} 0.9 \%$.
\end{abstract}

Keywords: Gastric Lavage, Ulcer Stress, Hemodynamic Status

Abstrak : Bilas Lambung, Stres Ulcer, Status Hemodinamik. Cidera kepala berat dengan post craniotomy di ruang intensif membutuhkan pemantauan yang ketat terkait peningkatan tekanan intrakranial dimana hal tersebut berisiko muncul stres fisiologis yaitu perdarahan gastrointestinal akut (stres ulcer) yang dapat mengganggu status hemodinamik (MAP, nadi) dan salah satu terapi yang biasa dilakukan yaitu bilas lambung. Untuk mengetahui pengaruh bilas lambung $\mathrm{NaCl} 0,9 \%$ terhadap status hemodinamik pada pasien stres ulcer dengan post craniotomy atas indikasi CKB di ruang Intensif Rumah Sakit Dr.Moewardi tahun 2015. Penelitian ini termasuk penelitian eksperimental dengan desain cross sectional terhadap 30 pasien stres ulcer post craniotomy atas indikasi cidera kepala yang dilakukan bilas lambung $\mathrm{NaCl} 0,9 \%$ di ruang ICU dan HCU RSUD Dr. Moewardi pada bulan Maret-Mei 2015. Analisis statistika yang digunakan adalah uji Paired Sample T-Test. Berdasarkan uji statistik, didapatkan hasil t hitung MAP 4,033 dengan nilai p 0,000 dan t hitung nadi 4,359 dengan nilai $p$ 0,000 dimana diketahui $t$ tabel 2,045 dan kriteria $p<0,05$. Sehingga nilai $t_{h}$ MAP $>t_{t}, t_{h}$ nadi $>t_{t}$ dan hasil MAP p 0,000 $(<0,05)$ dan nadi $p 0,000(<0,05)$. 
Terdapat pengaruh yang bermakna terhadap status hemodinamik pada pasien stres ulcer dengan post craniotomy atas indikasi cidera kepala berat yang dilakukan bilas lambung $\mathrm{NaCl} 0,9 \%$.

Kata Kunci: Bilas Lambung, Stres Ulcer, Status Hemodinamik

\section{PENDAHULUAN}

Angka kecelakaan lalu lintas per 100.000 penduduk di Jawa Tengah tahun 2012 sebesar 26,28 persen, pada tahun 2011 sebesar 94,80 persen. Sementara angka kematian akibat kecelakaan lalu lintas tahun 2012 adalah sebesar 0,93 persen. Dari semua kasus kecelakaan lalu lintas diatas, $60 \%$ adalah berupa cidera kepala.

Salah satu tatalaksana intensif pasien dengan cidera kepala berat yaitu pembedahan craniotomy. Pasien yang dilakukan tindakan craniotomy membutuhkan pemantauan dan perawatan intensif guna mencegah komplikasi salah satunya perdarahan saluran cerna bagian atas (Stres Ulcer) sebagai akibat adanya peningkatan tekanan intrakranial (TIK).

Insiden stress ulcer diluar stroke seperti cidera kepala berat, trauma abdomen $( \pm 18,9 \%)$. Ditemukan kelainan akut mukosa gastrointestinal 59 kasus dari 64 kasus stroke dimana pasien-pasien mengalami peningkatan tekanan intrakranial (TIK) yang disertai perdarahan pada gastrointestinal sejumlah 29 kasus $(45 \%)$

Pada tahun 2012 jumlah pasien bedah saraf (post craniotomy) atas indikasi cidera kepala berat terdapat 262 pasien, pada tahun 2013 terdapat 288 pasien, dan pada tahun 2014 terdapat 356 pasien.

Pasien post craniotomy a/i CKB selama praktek kritis bulan NovemberDesember 2014 sebanyak 20 pasien, pasien yang disertai komplikasi stres ulcer sebanyak 12 pasien dan 8 pasien tanpa disertai komplikasi stres ulcer. Dari angka tersebut $\pm 90 \%$ pria dalam rentang usia 45-64 tahun 7 orang, $>65$ tahun 5 orang.

Pasien post craniotomy dengan stres ulcer cenderung mengalami perubahan status hemodinamik dan diberi terapi bilas lambung untuk menghentikan perdarahan.

\section{METODE PENELITIAN}

Desain penelitian ini adalah quasi eksperimental design jenis pre and post test without control. Satu kelompok dilakukan observasi status hemodinamik pretest dan posttest bilas lambung $\mathrm{NaCl}$ $0,9 \%$. Analisa data pada penelitian ini menggunakan uji statististik parametrik Paired Sample T-Test pada taraf signifikan $95 \%$ dengan memperhatikan uji prasyarat yang meliputi uji normalitas dengan Shapiro-Wilk karena responden $<50$ dan uji homogenitas dengan One Way Anova.

\section{HASIL PENELITIAN}

\section{Tabel 1}

Distribusi Frekuensi Umur

\begin{tabular}{ccc}
\hline $\begin{array}{c}\text { Umur } \\
\text { (tahun) }\end{array}$ & Frekuensi & $\begin{array}{c}\text { Prosentase } \\
(\%)\end{array}$ \\
\hline $16-25$ & 4 & 13,3 \\
$26-35$ & 2 & 6,7 \\
$36-45$ & 6 & 20 \\
$>45$ & 18 & 60 \\
\hline Total & 30 & 100 \\
\hline
\end{tabular}

Frekuensi umur responden yang terbanyak yaitu usia diatas 45 tahun sebesar 18 responden $(60 \%)$. 
Tabel 2

\section{Distribusi Frekuensi Jenis Kelamin}

\begin{tabular}{ccc}
\hline $\begin{array}{c}\text { Jenis } \\
\text { Kelamin }\end{array}$ & Frekuensi & $\begin{array}{c}\text { Prosentase } \\
(\boldsymbol{\%})\end{array}$ \\
\hline Laki-laki & 22 & 73,3 \\
Perempuan & 8 & 26,7 \\
\hline Total & 30 & 100 \\
\hline
\end{tabular}

Frekuensi jenis kelamin responden yang terbanyak yaitu laki-laki sebesar 22 responden $(73,3 \%)$.

Adapun uji prasyarat yang harus dipenuhi meliputi:

Tabel 3

Hasil Uji Normalitas dengan ShapiroWilk

\begin{tabular}{lcc}
\hline \multicolumn{1}{c}{ Variabel } & $\mathbf{P}$ & Keterangan \\
\hline MAP pretest & 0,064 & Normal \\
MAP posttest & 0,501 & Normal \\
HR pretest & 0,122 & Normal \\
HR posttest & 0,560 & Normal \\
\hline
\end{tabular}

Tabel 4

Hasil Uji Homogenitas dengan One Way Anova

\begin{tabular}{cccc}
\hline Kriteria & MAP & Nadi & Ket \\
\hline $\mathrm{p}>0,05$ & 0,116 & 0,174 & Homogen \\
\hline
\end{tabular}

Sehingga data memiliki distribusi normal dan homogen.

Berikut hasil uji beda hemodinamik dengan uji Paired Sample T-Test:

\section{Tabel 5}

Perbedaan Nilai MAP dan Nadi Pre Post Bilas Lambung

\begin{tabular}{llccc}
\hline & Mean & $\begin{array}{c}\text { Std. } \\
\text { Deviation }\end{array}$ & $\begin{array}{c}\text { Std. } \\
\text { Error } \\
\text { Mean }\end{array}$ \\
\hline Pair 1 & MAP_Pre & 107.33 & 22.818 & 4.166 \\
& MAP_Pos & 97.90 & 16.151 & 2.949 \\
Pair 2 & HR_Pre & 110.63 & 25.302 & 4.619 \\
& HR_Post & 101.60 & 19.118 & 3.490 \\
\hline
\end{tabular}

Berdasarkan tabel 5, nilai mean MAP sebelum bilas lambung $\mathrm{NaCl} 0,9 \%$ 107,33 dan nilai mean MAP sesudah bilas lambung $\mathrm{NaCl}$ 0,9\% 97,90, maka ada perbedaan nilai mean MAP sebesar 9,43. Selain itu diketahui pula nilai mean nadi sebelum bilas lambung $\mathrm{NaCl}$ 0,9\% 110,63 dan nilai mean nadi sesudah bilas lambung $\mathrm{NaCl} \quad 0,9 \% \quad 101,60$, sehingga ada perbedaan nilai mean nadi sebesar 9,03 .

Tabel 6

Hasil Uji Paired T-Test Status

Hemodinamik Sebelum dan Sesudah Bilas Lambung NaCl 0,9\%

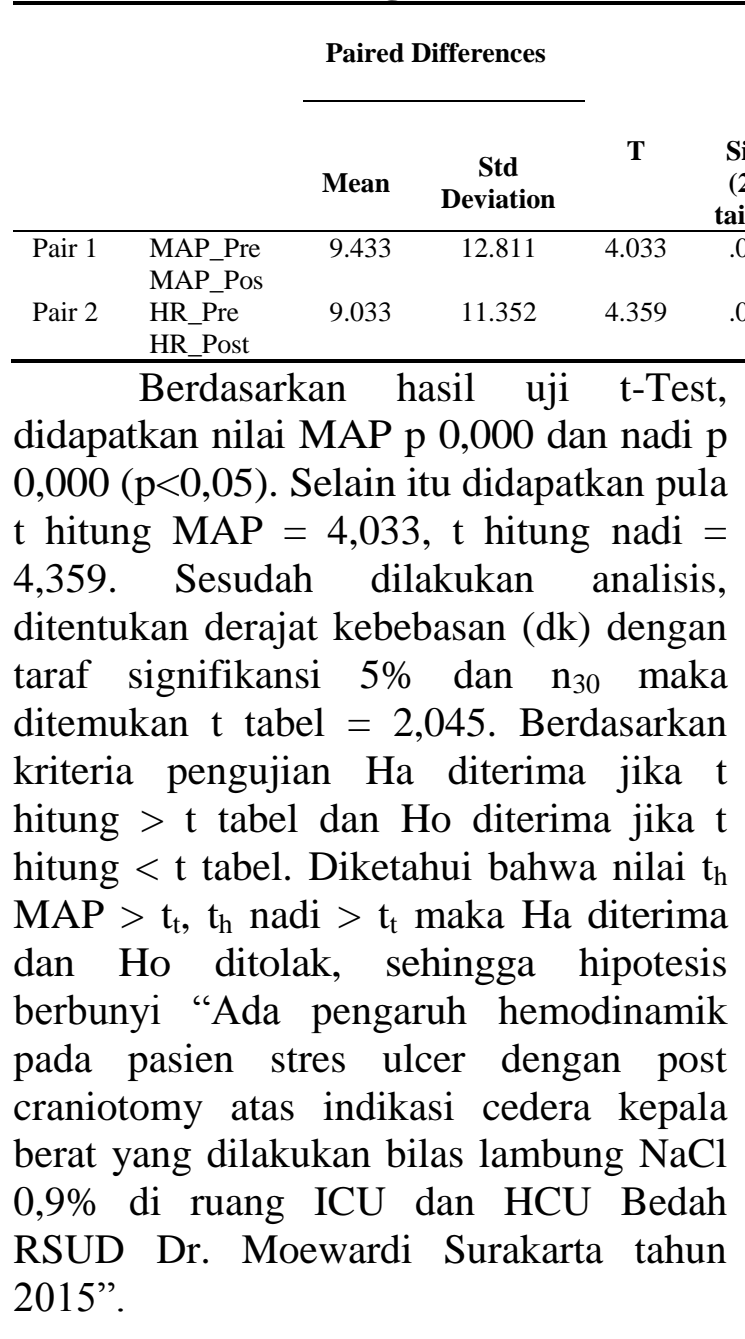

\section{PEMBAHASAN}

Hasil uji statistik pada penelitian ini diperoleh perbedaan yang signifikan 
antara nilai rata-rata MAP dan nadi sebelum dilakukan bilas lambung $\mathrm{NaCl}$ 0,9\% dengan sesudah dilakukan bilas lambung $\mathrm{NaCl} 0,9 \%$.

Hal ini didukung oleh teori Hudak dan Gallo (2012) bahwa pasien dengan post craniotomy harus dilakukan pemantauan ketat terhadap peningkatan tekanan intrakranial yang ditandai dengan perubahan status hemodinamik yang sering disebut sindrom chusing (peningkatan tekanan darah/ MAP, peningkatan nadi dan penurunan pernapasan). Apabila kondisi tersebut terus berkelanjutan tanpa ada tindakan dapat menjadi faktor resiko sindrom erosif terkait stres yang dapat menimbulkan komplikasi stres ulcer (perdarahan saluran cerna bagian atas).

Hal tersebut juga sependapat dengan Muhaj, Khadir (2009) bahwa pada umumnya pasien dengan cedera kepala berada dalam kondisi/keadaan stres fisiologi yang dapat mengganggu sistem metabolisme tubuh dengan memberi respon kepada hipotalamus untuk meningkatkan hormone adrenal dan katekolamin yang mempunyai efek meningkatkan sekresi asam lambung dan beresiko munculnya ulkus stres tergantung pada keparahan dan tipe penyakit sehingga dapat mempengaruhi nilai hemodinamik meliputi (peningkatan tekanan darah/ MAP dan nadi) dikarenakan adanya peningkatan frekuensi jantung dan vasokonstriksi vaskuler perifer sebagai upaya mempertahankan tekanan darah yang adekuat.

Bilas lambung $\mathrm{NaCl} \quad 0,9 \%$ terhadap responden yang dilakukan $2 \times 24$ jam sebanyak $200 \mathrm{ml}$ dalam penelitian ini menyatakan bahwa bilas lambung $\mathrm{NaCl}$ $0,9 \%$ dapat berpengaruh terhadap status hemodinamik sebagai indikator sindrom chusing dalam peningkatan tekanan intrakanial. Bilas lambung dalam penelitian ini menggunakan cairan isotonis dimana dapat memperbaiki permeabilitas vaskular yang meningkat sebagai akibat adanya stres fisiologis (stres ulcer) karena peningkatan tekanan intrakranial pada pasien post craniotomy. Hal ini dijelaskan pula dalam penelitian Trisnawati dan Munar (2008) dengan judul "Tatalaksana Peningkatan Tekanan Intrakranial (TIK) Akibat Trauma Kepala Berat pada Anak dengan Metode Bilas Lambung $\mathrm{NaCl}$ 0,9\% Dingin" bahwa metode tersebut sebagai neuroprotektif bila dilakukan sesegera mungkin dalam waktu kurang dari 48 jam pertama karena dapat mengurangi terjadinya gangguan pada sawar darah otak yang akan mengurangi stres fisiologis (stres ulcer), memperbaiki permeabilitas vaskuler karena berisiko syok akibat TIK meningkat dan berpengaruh terhadap kestabilan hemodinamik.

Selanjutnya didukung pula hasil penelitian Sarah (2012) dalam review artikel "Effect of Induction of Hypothermia for Intracranial Hypertension After Traumatic Brain Injury" yang menyebutkan bahwa terapi hipotermi yang dapat dilakukan dengan segera untuk mengatasi peningkatan tekanan intrakranial yang ditandai dengan sindrom chusing (peningkatan tekanan darah/ MAP, peningkatan nadi dan penurunan pernapasan) dan mencegah kerusakan neuron pasca trauma kepala salah satunya dengan bilas lambung $\mathrm{NaCl}$ $0,9 \%$ dingin $(\rho<0,05)$. Bilas lambung selain membantu membersihkan darah dari lambung dan membantu mengidentifikasi sumber perdarahan juga membantu memperbaiki sirkulasi (status 
hemodinamik) akibat peningkatan tekanan intrakranial.

Namun penelitian diatas ada yang tidak sependapat oleh teori Hudak, Gallo (2012) yang menyebutkan bilas lambung dengan cairan yang dingin (es) harus dihindari karena menyebabkan rasa tidak nyaman pada pasien, tidak dapat mengendalikan perdarahan, menurunkan suhu inti tubuh secara signifikan, dan dapat memicu disritmia jantung sedangkan terhadap status hemodinamik dapat mempengaruhi secara nyata dikarenakan mengantisipasi terjadinya sindrom chusing yang dapat berisiko tinggi syok pada pasien kasus trauma sehingga bilas lambung yang dilakukan dengan menggunakan normal salin \pm 250 $500 \mathrm{ml}$ dialirkan melalui selang nasogastrik. Normal saline (seperti $\mathrm{NaCl}$ $0,9 \%$ ) termasuk cairan isotonis dimana cairan tersebut memiliki tekanan osmotik yang sama seperti cairan tubuh dan sesuai diberikan pada pasien-pasien yang mengalami stres ulcer akibat sindrom erosif seperti cidera kepala berat karena diharapkan mampu menggantikan cairan yang hilang akibat perdarahan (stres ulcer) (Trisnawati dan Munar, 2008).

Selain itu Djojoningrat (2006) menyatakan bahwa bilas lambung dengan menggunakan larutan $\mathrm{NaCl}$ fisiologis sebaiknya dilakukan selain untuk tujuan diagnostik juga dalam usaha untuk menghentikan perdarahan dengan ditandai adanya perbaikan hemodinamik. Tehnik bilas lambung harus tepat agar tidak menimbulkan trauma mukosa saluran cerna terutama pasien-pasien dengan kasus trauma berat yang berada pada kondisi/ keadaan stres fisiologis.

Hal tersebut didukung pula oleh penelitian Djumhana (2009) bahwa pasien dengan perdarahan saluran cerna bagian atas (stres ulcer) untuk penilaian hemodinamik (keadaan sirkulasi) perlu dilakukan evaluasi jumlah perdarahan. Perdarahan $<8 \% \quad$ menunjukkan hemodinamik stabil, perdarahan $8-15 \%$ menunjukkan hipotensi maupun hipertensi ortostatik, perdarahan 15-25\% menunjukkan renjatan (syok), perdarahan $25-40 \%$ menunjukkan renjatan disertai penurunan kesadaran, dan perdarahan $>40 \%$ menunjukkan moribund. Evaluasi terhadap perdarahan tersebut dapat dilakukan dengan bilas lambung untuk mengetahui aspirat melalui naso gastric tube (NGT). Prosedur ini selain untuk diagnostik dapat dipakai pula untuk terapi. Prosedur ini tidak perlu dilakukan segera (bukan prosedur emergensi), dapat dilakukan dalam kurun waktu 12-24 jam setelah pasien masuk dan membuat keadaan hemodinamik stabil.

Sehingga disimpulkan menurut Japardi (2007) yang menyatakan bahwa perdarahan akut saluran cerna bagian atas (stres ulcer) sering menyertai penyakit trauma kapitis. Hal tersebut mampu mempengaruhi status hemodinamik yang tidak stabil. Perubahan ini dimulai ketika terjadi trauma kapitis, kondisi fisiologis tubuh mengalami stres sehingga beresiko munculnya ulkus stres pada sistem gastrointestinal tergantung pada tingkat keparahan dan tipe penyakit sebagai akibat dari sel-sel mukosa yang tidak menghasilkan produksi mukus yang adekuat sebagai perlindungan terhadap asam lambung sehingga menyebabkan hipoksia jaringan mukosa, cedera atau kematian sel-sel penghasil mukus. Penurunan aliran darah terjadi pada semua jenis syok dan pada kasus trauma kapitis tersebut ditandai dengan sindrom chusing (peningkatan tekanan darah/ MAP, peningkatan nadi dan penurunan 
pernapasan) dikarenakan adanya peningkatan frekuensi jantung dan vasokonstriksi vaskuler perifer. Dan salah satu terapi yang digunakan yaitu bilas lambung dengan cairan fisiologis selain membantu membersihkan, mengeliminasi perdarahan yang ada di gastrointestinal juga dapat sebagai pengganti cairan yang adekuat dengan cairan isotonis. Yang mana hal tersebut akan berdampak pada status hemodinamik misal tekanan darah/MAP dan nadi akan menjadi turun atau normal.

\section{KESIMPULAN DAN SARAN}

Berdasarkan hasil uji paired sampel t-test didapatkan nilai MAP $\mathrm{p}$ $0,000$ dan nadi p 0,000 ( $\mathrm{p}<0,05)$. Selain itu didapatkan pula $t$ hitung MAP $=4,033$, $\mathrm{t}$ hitung nadi $=4,359$, sedangkan $\mathrm{t}$ tabel didapatkan nilai $\mathrm{t}_{29,0,05}=2,045$. Diketahui bahwa nilai $\mathrm{t}$ hitung $>\mathrm{t}$ tabel maka $\mathrm{Ha}$ diterima dan Ho ditolak yang berarti ada pengaruh yang bermakna pada status hemodinamik (MAP dan nadi) sebelum dan sesudah diberikan tindakan bilas lambung $\mathrm{NaCl} 0,9 \%$ pada pasien stres ulcer dengan post craniotomy atas indikasi cidera kepala.

Berdasarkan hasil penelitian tersebut maka sangatlah perlu bagi perawat untuk menjadikan sebagai referensi dan pengetahuan yang mampu dikembangkan untuk memberikan pelayanan kepada pasien yang lebih berkualitas dengan mengikuti perkembangan ilmu pengetahuan. Salah satunya tindakan bilas lambung $\mathrm{NaCl}$ $0,9 \%$ terhadap status hemodinamik pasien stres ulcer.

\section{DAFTAR RUJUKAN}

Carolyn, M.H., \& Barbara, M.G. (2012). Keperawatan Kritis Pendekatan
Holistik, Edisi VI Vol 2. Alih bahasa: Allenideknia dkk. Jakarta: IKAPI

Djumhana, A.H. (2009). Perdarahan Saluran Cerna Bagian Atas. Pusat penerbitan Departemen ilmu penyakit dalam FK UnpadBandung

Djojoningrat, D. (2006). Pendekatan Klinis Penyakit Gastrointestinal Dalam Sudoyo, A. W., Setiyohadi, B., Alwi, I., Simadibrata M., Setiati, S. (edisi IV Jilid I) Buku Ajar Ilmu Penyakit Dalam. Jakarta: Pusat penerbitan Departemen ilmu penyakit dalam FK-UI

Japardi, I. (2007). Tekanan Tinggi Intrakranial. Pusat penerbitan Departemen ilmu bedah FK-USU. Terdapat di (http://repository.usu.ac.id/), diakses tanggal 16 Mei 2015

Muhaj, K. (2009). Laporan Pendahuluan Cedera Kepala. Terdapat di (http://khaidirmuhaj.com/2009/03/ askep-cedera-kepala.html), diakses tanggal 11 Januari 2015

Sarah, S. (2012). Artikel Review Effect of Induction of Hypothermia for Intracranial Hypertension After Traumatic Brain Injury. International of Medical Research

Trisnawati, Y., \& Munar. (2008). Tatalaksana Peningkatan Tekanan Intrakranial Akibat Trauma Kepala Berat pada Anak dengan Metode Bilas Lambung $\mathrm{NaCl}$ 0,9\% Dingin. USU Institutional Repository. Terdapat didalam web (http://repository.usu.ac.id/bitstrea $\mathrm{m} / 123456789 / 18621 / 1 / \mathrm{mkn}$ des2008-41\%20(12).pdf), diakses tanggal 16 Mei 2015 